\title{
Durability and Tolerability of Fosamprenavir/Ritonavir Containing Regimens in HIV-Infected Patients with or without Hepatitis B or C Co-Infection: Results from a Large French Cohort in Clinical Practice
}

\author{
Dellamonica $\mathbf{P}^{1}$, Katlama $\mathbf{C}^{2}$, Cabié $\mathbf{A}^{3}$, Texier $\mathbf{N}^{4}$ and Finkielsztejn $\mathbf{L}^{5^{*}}$ \\ ${ }^{1}$ Service of Infectious and Tropical Diseases, Hôpital l'Archet, Nice, France \\ ${ }^{2}$ Service of Infectious and Tropical Diseases CHU Pitié Salpêtrière, France \\ ${ }^{3}$ Service of Infectious and Tropical Diseases, $\mathrm{CHU}$ de Martinique, France \\ ${ }^{4}$ Kappa Santé, Paris, France \\ ${ }^{5}$ ViiV Healthcare, Marly le Roi, France
}

"Corresponding author: Laurent Finkielsztejn, Medical Department, ViiV Healthcare, 100 route de Versailles, Marly-Le-Roi 78163, Cedex, France, Tel: +33139176906; E-mail: Laurent.1.finkielsztejn@viivhealthcare.com

Received date: July 25, 2014, Accepted date: October 29, 2014, Published date: November 09, 2014

Copyright: @ 2014 Finkielsztejn L, et al. This is an open-access article distributed under the terms of the Creative Commons Attribution License, which permits unrestricted use, distribution, and reproduction in any medium, provided the original author and source are credited.

\section{Abstract}

Background: We investigated whether tolerance and durability were different according to the presence or absence of co-infection (hepatitis B and/or hepatitis C virus) among a cohort of HIV-1 patients treated with fosamprenavir/r (FPV/r) containing regimen.

Methods: Data were collected from 7 large HIV reference medical centers in France. We selected adult HIV-1 infected patients who were receiving an antiretroviral combination including FPV/r between January 2004 and December 2007. Date and reason for FPV/r discontinuation were recorded. Time to treatment discontinuation was analyzed by Kaplan Meier survival method.

Results: In total, 1279 patients treated with FPV/r containing regimen were analysed in the study period out of them $20 \%$ were ART (antiretroviral therapy)-naive. 460 patients were hepatitis co-infected (13\% are ART naive), $74 \%$ with $\mathrm{HCV}, 17 \%$ with HBV, $6 \%$ both. 263 co-infected patients (57.2\%) and 469 mono-infected patients (57.2\%) discontinued the FPV/r-including regimen after a median duration of 23 months, with no difference between coinfected and non-co-infected patients, at 23.2 months $(95 \% \mathrm{Cl} 19.3-27.7)$ and 23.0 months (95\% Cl 20.3-25.5), respectively. Tolerability issues were the main reason for early discontinuation and among them gastro-intestinal (GI) adverse effects were the most frequent.

Conclusion: In summary, antiviral therapy including FPV/r provides similar durability in HIV/HCV or HBV coinfected patients as in HIV mono-infected patients, for both naïve and experienced patients.

Keywords: Antiretroviral therapy; Fosamprenavir; HIV; Hepatitis co-infection; Protease inhibitor

\section{Introduction}

In Western Europe and USA, 25 to $30 \%$ of HIV infected patients are co-infected with hepatitis C virus (HCV) and 6 to $14 \%$ with hepatitis $\mathrm{B}$ virus (HBV) [1]. Co-infected patients are at higher risk of liver failure, cirrhosis or hepatocellular carcinoma and also of hepatotoxicity related to antiretroviral therapy (ART) [2,3]. Several mechanisms are involved in ART hepatotoxicity and some antiretrovirals, i.e. nevirapine and efavirenz are more frequently associated with liver toxicity than others [4].

Fosamprenavir boosted with ritonavir (FPV/r), the phosphate ester prodrug of the protease inhibitor (PI) amprenavir, has been shown in clinical trials to be an effective component of PI-based combination either in a twice daily (FPV/r 700/100 mg BID) [5-10] or in a once daily dosage (FPV/r 1400/100 mg) and FPV/r containing regimens are recommended in naïve and experienced patients [11-14].
Long term tolerability data up to 8 years for $\mathrm{FPV} / \mathrm{r}$ containing regimens have been documented $[15,16]$ but are limited in hepatitis co-infected patients. Overall, the rate of grade 3/4 liver enzymes elevations (LEE) ranged from $3 \%$ to $5 \%$ in trials evaluating $\mathrm{FPV} / \mathrm{r}$ in first line regimen and from 8 to $24 \%$ in the sub-group of co-infected patients [5-9]. A posthoc analysis over 48 weeks of 7 prospective clinical trials with different dosing of FPV/r including 205 co-infected and 1114 mono-infected patients showed a similar rate of treatmentrelated severe adverse events between the 2 groups (at 8 and 6\%, respectively) and a higher rate of grade $3 / 4$ liver enzyme elevation in the co-infected group (AST 12\%, ALT 14\% vs. $1 \%$ for both) [17].

Most data available are issued from comparative randomized placebo controlled clinical trials; few studies have evaluated safety in real-life setting for HCV/HBV co-infected patients. In a large population of patients receiving $\mathrm{FPV} / \mathrm{r}$, the incidence of adverse hepatic events was low even in co-infected patients $(0.58 \%$ and $2.63 \%$ in HCV and HBV co-infected patients, respectively) [18]. Similar results were observed in another study in which no differences 
Citation: Dellamonica P, Katlama C, Cabié A, Texier N, Finkielsztejn L (2014) Durability and Tolerability of Fosamprenavir/Ritonavir Containing Regimens in HIV-Infected Patients with or without Hepatitis B or C Co-Infection: Results from a Large French Cohort in Clinical Practice. J AIDS Clin Res 5: 372. doi:10.4172/2155-6113.1000372

Page 2 of 6

between FPV/r and other boosted PIs in term of severe liver toxicity were reported [19].

Like many other ARV, FPV can be used with caution in patients with severe liver failure [20] and requires dosage adaptation [14]. Additional data on long term toxicity and tolerability of FPV/r in coinfected patients are needed in real life setting. The objective of this multicenter observational study was to assess the tolerability and durability of the FPV/r-including regimen in a large cohort of HIV patients with a focus on HBV or HCV co-infected patients.

\section{Patients and Methods}

\section{Study design}

The cross-sectional study collected data from 7 large HIV medical centres in France using the same electronic medical record system (EMRS), Nadis ${ }^{\oplus}$, for the medical follow-up of HIV-infected patients (Fort-de-France, Marseille, Nantes, Nice, Paris, Toulouse, and Tourcoing) [18]. All the patients gave their written consent to be included and to have their medical data recorded in this EMRS, including demographic details, medical history, HIV disease history, clinical events, antiretroviral history, plasma viral load measurements, CD4 cell count and laboratory data throughout follow-up. Standardized quality control assessments are performed annually in each center.

We enrolled in the study, amprenavir or FPV-naïve HIV-1 infected adults were included in the study if they initiated a FPV/r-including regimen from January 2004 to December 2007 for any of the following reasons: first line ARV regimen, switch strategy with an undetectable viral load HIV-1 RNA level (VL) below 50 copies/ml, or clinical virological failure. Naïve (first line regimen) and experienced patients (previously treated with ART regimens) were divided in two groups for the purpose of the analysis.

Demographical, clinical assessments and HIV related information were collected at regular 3-6 month intervals during routine clinical assessment. HBV-infection was defined as hepatitis B surface antigen (Hbs Ag) positive; $\mathrm{HCV}$-infection was defined as anti-hepatitis $\mathrm{C}$ antibody positive. Date of serology and treatment were recorded.

\section{Evaluation criteria}

The study aims at investigating whether durability and tolerance were different according to the viral hepatitis co-infection status (HBV and/or HCV) among the HIV-1 patients cohort.

The primary endpoint of the study was the time to the first treatment discontinuation of the FPV/r-including regimen. In case of $\mathrm{FPV} / \mathrm{r}$-including regimen, the date and cause were recorded. Reasons of discontinuation were classified as intolerance (any adverse event leading to discontinuation), virological failure (defined as $\mathrm{VL}>50$ copies $/ \mathrm{ml}$ at the time of discontinuation or after 6 months of treatment), or other causes (i.e. poor adherence, pregnancy, inclusion in a clinical trial). Virological success was defined as a VL below 50 copies $/ \mathrm{ml}$.

Secondary endpoints include main reasons leading to intolerance discontinuation description and the percentage of patients with grade 2 and $3 / 4$ aspartate aminotransferase (AST) and alanine aminotransferase (ALT) elevations during the $\mathrm{FPV} / \mathrm{r}$ regimens (respectively values 2 to 5 times the Upper Limit of Normal (ULN) for grade 2 and $>5$ times the ULN for grade 3 to 4 ).

\section{Statistical analysis}

All analyses were done in the naïve and experienced patients according to the presence or absence of HCV or HBV co-infection. Descriptive statistics (means, proportions and quartile) were used to summarize the data in these groups. Time to treatment discontinuation was analyzed by Kaplan Meier survival method. Follow-up was censored if the patient discontinued FPV/r containing regimens, died, or at the censoring date (31 may 2008), whichever occurred first. If the patient was lost to follow-up, the last date of medical visit was considered as date of last news. Statistical analyses were performed with the use of SAS software version 9.1 (SAS Institute, NC, USA).

\section{Results}

\section{Baseline patients characteristics}

From January 2004 to December 2007, a total of 1279 subjects were included in the study (1939 person-years) with $256(20 \%)$ patients in the ART naive group and 1023 (80\%) in the experienced group with 355 (28\%) patients of them switching to a FPV-including regimen and 668 (52\%) patients started the FPV-including regimen as part of an optimized base regimen. Experienced patients had previously received 5 antiretroviral combinations.

Mean $( \pm$ SD) age of the total cohort was $43( \pm 9)$ years and 900 $(70.4 \%)$ were male. $36 \%(n=460)$ of the subjects were co-infected with $\mathrm{HBV}$ and/or HCV corresponding to 684 person-years. Out of them $74.1 \%, 17.2 \%$ and $5.7 \%$ were $\mathrm{HCV}, \mathrm{HBV}$ and $\mathrm{HCV} / \mathrm{HBV}$ co-infected (no information for $3 \%$ ), respectively. $30 \%$ of the patients were at stage $\mathrm{CDC} \mathrm{C}$ at initiation of $\mathrm{FPV} / \mathrm{r}$ therapy.

\section{Characteristics of the patients at initiation of FPV/r therapy}

Baseline characteristics appeared well-balanced between co-infected and mono-infected groups, for -naïve and experienced patients (Table $1)$.

Time from HIV diagnosis was significantly higher in co-infected than in mono-infected patients (naive group 7.2 vs. 1 year and experienced group 15.2 vs. 11 years). Mean baseline viral load was significantly higher in co-infected naïve patients compared with nonco-infected naïve patients at $4.8 \log 10$ copies/ml and $5.2 \log 10$ copies $/ \mathrm{ml}$, respectively $(\mathrm{p}<0.01)$. In the experienced population, mean baseline CD4+ cell count was significantly lower in co-infected than in non-co-infected patients at 341 and 394 cells per $\mathrm{mm}^{3}$, respectively $(\mathrm{p}<0.0001)$.

No difference was seen in baseline grade $3 / 4$ liver enzyme elevations between mono-infected and co-infected patients (AST 1.3\% vs. $3 \%$ and ALT $1.1 \%$ vs. $2.7 \%$ ). Grade 2 AST and ALT rates were higher in coinfected patients vs. mono-infected patients (respectively $11 \%$ vs. $1.8 \%$ and $11 \%$ vs. $2.6 \%$ ).

In the naive group, $90 \%$ of the subjects received a triple drug therapy based on two nucleoside reverse transcriptase inhibitors (NRTI) combined with FPV/r, regardless of the presence or absence of co-infection. 
Citation: Dellamonica P, Katlama C, Cabié A, Texier N, Finkielsztejn L (2014) Durability and Tolerability of Fosamprenavir/Ritonavir Containing Regimens in HIV-Infected Patients with or without Hepatitis B or C Co-Infection: Results from a Large French Cohort in Clinical Practice. J AIDS Clin Res 5: 372. doi:10.4172/2155-6113.1000372

Page 3 of 6

\begin{tabular}{|c|c|c|c|c|c|c|}
\hline \multirow[t]{2}{*}{ Characteristics } & \multicolumn{3}{|c|}{ Naive $^{*}$ patients } & \multicolumn{3}{|c|}{ Experienced patients } \\
\hline & $\begin{array}{l}\text { Without } \\
\text { co-infection } \\
(\mathrm{N}=195)\end{array}$ & $\begin{array}{l}\text { With } \\
\text { co-infection } \\
(\mathrm{N}=61)\end{array}$ & $\mathrm{P}^{* *}$ & $\begin{array}{l}\text { Without } \\
\text { co-infection } \\
(\mathrm{N}=624)\end{array}$ & $\begin{array}{l}\text { With } \\
\text { co-infection } \\
(\mathrm{N}=399)\end{array}$ & $P^{* *}$ \\
\hline \multicolumn{7}{|l|}{ Sex } \\
\hline Male & $138(70.8 \%)$ & $42(68.9 \%)$ & 0,77 & $427(68.4 \%)$ & $293(73.4 \%)$ & 0,09 \\
\hline \multicolumn{7}{|l|}{ Age in years } \\
\hline Median (range) & $39(18-82)$ & $41(21-66)$ & & $42(18-79)$ & $43(22-79)$ & \\
\hline \multicolumn{7}{|c|}{ Time from HIV-positive in years } \\
\hline Median (range) & $1(0-20)$ & $7.2(0-24.3)$ & $<0,0001$ & $11(0-23.3)$ & $15.2(0.1-25.3)$ & $<0,0001$ \\
\hline \multicolumn{7}{|l|}{ CDC classification $\mathrm{C}$} \\
\hline Yes & $39(20 \%)$ & $12(19.7 \%)$ & 0,96 & $204(32.7 \%)$ & $123(30.8 \%)$ & 0,53 \\
\hline \multicolumn{7}{|c|}{ HIV-1 RNA log10 copies per mL } \\
\hline Mean $( \pm S D)$ & $5.2( \pm 0.8)$ & $4.8( \pm 0.9)$ & $<0.01$ & $3.3( \pm 1.5)$ & $3.3( \pm 1.5)$ & 0.65 \\
\hline$>5 \log 10$ copies per $\mathrm{mL}$ & $109(65.3 \%)$ & $23(50 \%)$ & 0.06 & $99(15.9 \%)$ & $62(15.5 \%)$ & 0.89 \\
\hline Missing value & 28 & 15 & & 0 & 0 & \\
\hline \multicolumn{7}{|c|}{ CD4+ cell count in cells per mL } \\
\hline Mean $( \pm S D)$ & $210( \pm 140)$ & $197.7( \pm 164.5)$ & 0.61 & $394.3( \pm 251.7)$ & $341( \pm 244.7)$ & $<0.0001$ \\
\hline Missing value & 26 & 16 & & 5 & 5 & \\
\hline \multicolumn{7}{|l|}{ ALT Grade } \\
\hline Normal & $102(81 \%)$ & $32(80 \%)$ & $0,91^{\star *}$ & $414(83.5 \%)$ & $188(58 \%)$ & $<0,001$ \\
\hline Grade 1/2 & $22(17.5 \%)$ & $7(17.5 \%)$ & & 77 (15.5\%) & $127(39.2 \%)$ & \\
\hline Grade 3/4 & $2(1.6 \%)$ & $1(2.5 \%)$ & & $5(1 \%)$ & $9(2.8 \%)$ & \\
\hline Missing & 69 & 21 & & 128 & 75 & \\
\hline \multicolumn{7}{|l|}{ AST Grade } \\
\hline Normal & $107(84.9 \%)$ & $27(67.5 \%)$ & $0.02^{* *}$ & $433(87.2 \%)$ & $167(51.3 \%)$ & $<0.001$ \\
\hline Grade $1 / 2$ & $18(13.3 \%)$ & $11(28 \%)$ & & 57 (11.5\%) & $149(45.8 \%)$ & \\
\hline Grade 3/4 & $1(0.8 \%)$ & $2(5 \%)$ & & $6(1.2 \%)$ & $9(2.8 \%)$ & \\
\hline Missing & 69 & 21 & & 128 & 74 & \\
\hline
\end{tabular}

Table 1: Description of baseline characteristics. *"naive patients": FPV/r used as a part as the first regimen. ${ }^{*}$ exact fisher test

In experienced patients, triple drug therapy was used by $77 \%$ of the co-infected patients and $70 \%$ of the patients without co-infection. The $2^{\text {nd }}$ most frequent regimens associated with $\mathrm{FPV} / \mathrm{r}$ in experienced patients were based on one NRTI and one non-nucleoside reverse transcriptase inhibitor (NNRTI) (respectively $1.8 \%$ and $2.9 \%$ of coinfected and mono-infected patients) and on one NRTI and a second PI (respectively $0.5 \%$ and $1.4 \%$ of co-infected and mono-infected patients).

\section{FPV/r treatment discontinuation}

Overall a treatment discontinuation occurred in $57.2 \%$ of the patients $(n=732)$ for the global cohort on FPV-including regimen with a mean duration on treatment of 23.2 months $(95 \%$ CI $=[20.7-$ 25.1]). The rate of discontinuation was similar (57.2\%) in the coinfected group $(n=263)$ and in the mono HIV infected $(n=469)$ with a similar median time of FPV discontinuation, respectively 23.2 months $(95 \% \mathrm{CI}=[19.3$ to 27.7$])$ and 23.0 months $(95 \% \mathrm{CI}=[20.3$ to 25.5$])$ (Figure 1). The FPV/r treatment was discontinued within the first 6 months for $39 \%$ of the co-infected patients $(n=103)$ (Table 2). 
Citation: Dellamonica P, Katlama C, Cabié A, Texier N, Finkielsztejn L (2014) Durability and Tolerability of Fosamprenavir/Ritonavir Containing Regimens in HIV-Infected Patients with or without Hepatitis B or C Co-Infection: Results from a Large French Cohort in Clinical Practice. J AIDS Clin Res 5: 372. doi:10.4172/2155-6113.1000372

Page 4 of 6

\begin{tabular}{|c|c|c|c|c|c|c|}
\hline & \multicolumn{3}{|c|}{ Naive* patients } & \multicolumn{3}{|c|}{ Experienced patients } \\
\hline & $\begin{array}{l}\text { Without } \\
\text { co-infection } \\
(\mathrm{N}=195)\end{array}$ & $\begin{array}{l}\text { With } \\
\text { co-infection } \\
(\mathrm{N}=61)\end{array}$ & $p^{* *}$ & $\begin{array}{l}\text { Without } \\
\text { co-infection } \\
(\mathrm{N}=624)\end{array}$ & $\begin{array}{l}\text { With } \\
\text { co-infection } \\
(\mathrm{N}=399)\end{array}$ & $\mathrm{p}^{\star *}$ \\
\hline \multicolumn{7}{|l|}{ FPV/r discontinuation } \\
\hline & $110(56.4 \%)$ & $40(65.6 \%)$ & $0.20^{\star *}$ & $359(57.5 \%)$ & $223(55.9 \%)$ & $0.60^{\star *}$ \\
\hline \multicolumn{7}{|l|}{ Discontinuation reasons } \\
\hline Intolerance & $30(15.4 \%)$ & $16(26.2 \%)$ & 0.55 & $123(19.7 \%)$ & $64(16.0 \%)$ & *** \\
\hline Simplification & $33(16.9 \%)$ & $9(14.8 \%)$ & & $41(6.6 \%)$ & $15(3.8 \%)$ & \\
\hline Death & $3(1.5 \%)$ & $0(0 \%)$ & & $1(0.2 \%)$ & $8(2.0 \%)$ & \\
\hline Immuno-virological failure & $19(9.7 \%)$ & $5(8.2 \%)$ & & $107(17.1 \%)$ & $58(14.5 \%)$ & \\
\hline Other ${ }^{* * *}$ & $25(12.8 \%)$ & $10(16.4 \%)$ & & $87(13.9 \%)$ & $78(19.5 \%)$ & \\
\hline \multicolumn{7}{|c|}{ Reasons for FPV/r discontinuation due to intolerance } \\
\hline Digestive side effects & $12(6.2 \%)$ & $10(16.4 \%)$ & & $51(8.2 \%)$ & $18(4.5 \%)$ & \\
\hline Biological toxicity ${ }^{\star * *}$ & $6(3.1 \%)$ & $1(1.6 \%)$ & & $15(2.4 \%)$ & $7(1.8 \%)$ & \\
\hline Lipodystrophy & $4(2.1 \%)$ & $0(0 \%)$ & & $10(1.6 \%)$ & $4(1.0 \%)$ & \\
\hline Drug intolerance / toxicity & $4(2.1 \%)$ & $1(1.6 \%)$ & & $10(1.6 \%)$ & $8(2.0 \%)$ & \\
\hline Cutaneous side effects /HSR & $1(0,5 \%)$ & $2(3.2 \%)$ & & $15(2.4 \%)$ & $7(1.8 \%)$ & \\
\hline Liver toxicity & $1(0.5 \%)$ & $1(1.6 \%)$ & & $1(0.2 \%)$ & $9(2.2 \%)$ & \\
\hline Neuro-/psychiatric side effects & $0(0 \%)$ & $0(0 \%)$ & & $6(1.0 \%)$ & $1(0.3 \%)$ & \\
\hline Cardiovascular side effects & $0(0 \%)$ & $0(0 \%)$ & & $0(0 \%)$ & $3(0.8 \%)$ & \\
\hline Musculoskeletal side effects /myositis & $0(0 \%)$ & $0(0 \%)$ & & $3(0.5 \%)$ & $0(0 \%)$ & \\
\hline Renal side effects & $0(0 \%)$ & $0(0 \%)$ & & $1(0.2 \%)$ & $0(0 \%)$ & \\
\hline Other side effects & $2(1.0 \%)$ & $1(1.6 \%)$ & & $11(1.8 \%)$ & $7(1.8 \%)$ & \\
\hline
\end{tabular}

Table 2: Discontinuation rate and reasons for FPV/r discontinuation according to the absence or presence of HCV and/or HBV co-infection. * "naïve patients": FPV/r used as a part as the first regimen; ${ }^{\star *}$ exact Fisher test; ${ }^{* * *}$ chisquare test non applicable; ${ }^{* *}$ others including patients' decision, adjustement and others reason; ${ }^{* * *}$ biological toxicity includes dyslipidaemia, haematological toxicity and other biological toxicity.

Overall, $58.6 \%$ of the naive and $56.9 \%$ of the experienced patients stopped their FPV/r-including regimen. The proportion of treatment discontinuation was higher in the co-infected patients than in the patients without co-infection at $65.6 \%$ and $56.4 \%$, in the naive group and at $57.5 \%$ and $55.9 \%$ in the experienced group, respectively, without any significant difference (Table 2).

The most frequent reasons for treatment discontinuation were drug intolerance (18.2\%), immuno-virological failure (14.8\%) and patient's decision (8.3\%). Main drug intolerances were GI disorders (7.1\%) and biological side effects (2.3\%). The proportion of discontinuation due to intolerance among all discontinuation causes was not significantly different for patients with and without co-infection (Table 2). GI disorders leading to discontinuation were more frequent in co-infected naïve patients than in non-co-infected naïve patients ( $16.4 \%$ vs. $6.2 \%)$ and less frequent in the co-infected experienced patients than in the non-co-infected experienced patients $(4.5 \%$ vs. $8.2 \%)$. During the follow-up, 12 patients died, 4 mono-infected patients and 8 coinfected patients. One co-infected patient died of liver damage.

\section{Liver toxicity and FPV containing regimens}

A total of 12 patients discontinued their FPV/r containing regimen for liver toxicity; out of them, discontinuation occurred in the first 6 months for 10 patients and the majority were experienced and coinfected $(n=9)$.

After FPV/r initiation, 26\% of the co-infected patients ( $\mathrm{n}=95)$ presented an ALT elevation and $22 \%$ an AST elevation $(n=81)$. Most of them were grade 1 or $2,5.8 \%(n=21)$ and $3.8 \%(n=14)$ were grade $3 / 4$ ALT and AST, respectively.

$53.6 \%$ and $56.7 \%$ of the co-infected patients with normal aminotransferase values at baseline had no modifications observed during the whole observational phase. Six patients out of the 10 
Page 5 of 6

patients with grade 3/4 ALT elevation and 6/11 with grade 3/4 AST elevation at baseline showed an improvement of the liver function test during the $\mathrm{FPV} / \mathrm{r}$ therapy.

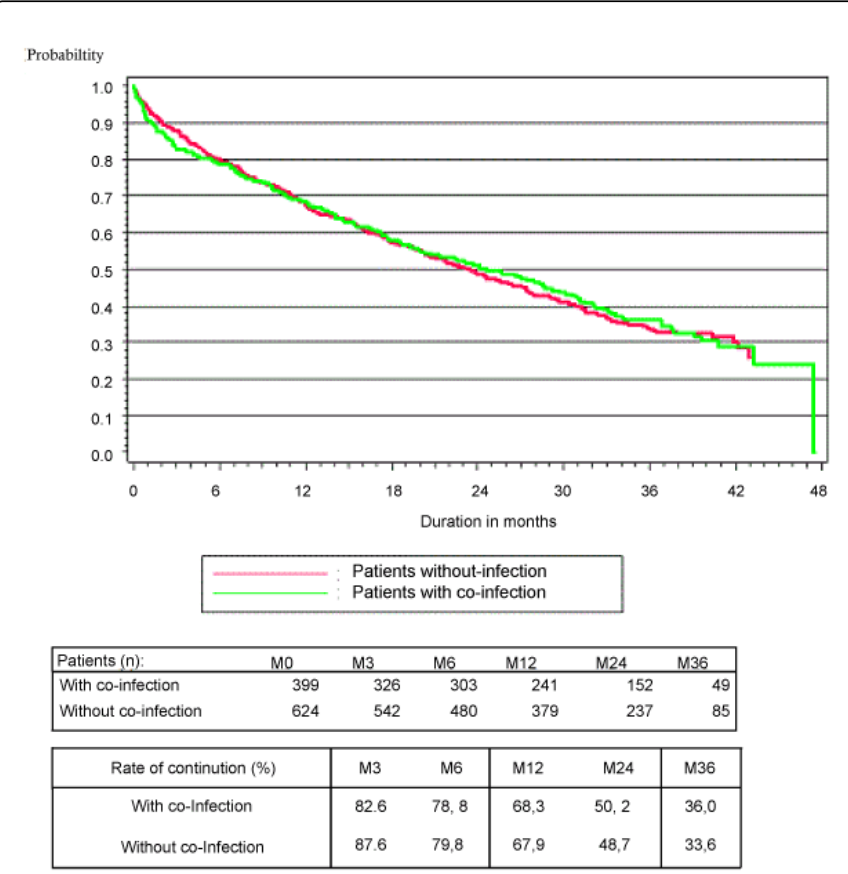

Figure 1: Time to FPV/r discontinuation regardless of presence and absence of HCV and/or HBV co-infection.

\section{Discussion}

The present observational study shows that FPV/r has been largely used in HIV infected patients, particularly in co-infected patients and provides additional data on it use in real-life setting conditions for patients with viral hepatitis co-infection.

The study was conducted in a large cohort of patients treated with FPV/r containing regimens (1939 person-years), including patients with and without $\mathrm{HBV} / \mathrm{HCV}$ co-infections with no selective criteria on the disease severity or on other ART or HCV/HVB treatments. The global cohort as well as the group of co-infected patients are larger than those described in a recently published meta-analysis of FPV/r clinical trials [17] or than previous observational studies [15,18-19] and include both treatment naïve and experienced patients.

The study shows that FPV/r containing regimens are frequently used in co-infected patients $(36 \%$ in our study vs. $25 \%$ for other treatment in the global Information New Aids Data Information System) [20]. This suggests that FPV/r was preferably given to a highly experienced population with hepatic risk, as confirmed by the higher median number of lines received before $\mathrm{FPV} / \mathrm{r}$ therapy compared to the global cohort. The description of patients shows similar characteristics between mono-infected and co-infected patients in terms of age, gender and HIV history.

In the present study, more than one-half of naïve and experienced patients discontinued their treatment, in the same range as the study discontinuation rate of $44 \%$ in the FPV/r long term safety study [15]. However we observed no significant differences in frequency of $\mathrm{FPV} / \mathrm{r}$ discontinuation among participants that were co-infected and those that were not co-infected with a median time of 23 months to FPV/r discontinuation is similar in both groups. In mono-infected and coinfected patients, the main cause of $\mathrm{FPV} / \mathrm{r}$ combination's discontinuation is intolerance (18\%). Interruptions for intolerance were mainly associated with GI disorders which are in accordance with the tolerability profile of FPV/r $[15,21]$. In our study GI disturbance do not seem more frequent in co-infected patients than in non-co-infected patients. Discontinuation for liver toxicity was low in both groups ( $2 \%$ in co-infected patients) and occurred mainly during the first 6 months of treatment.

Grade 3/4 liver enzyme elevation during FPV/r regimens were infrequent in the co-infected group (5.8\% for ALT and 3.8\% for AST) and confirm that use of $\mathrm{FPV} / \mathrm{r}$ has a satisfactory safety profile in patients with HVC or HVB co-infections. Those results confirm those of observational studies with a low occurrence of hepatic adverse events in patients treated with $\mathrm{FPV} / \mathrm{r}$ regimen with and without hepatitis co-infection $[15,18]$ and are comparable to other boosted PIs [19]. Occurrence of hepatic adverse events has recently been shown more frequent with $\mathrm{PI} / \mathrm{r}$ including regimen in naïve $\mathrm{HCV}$ co-infected patients (10.5\% patients with grade 3/4 AST/ ALT elevation) [22]. Though, no data are specifically presented for patients receiving FPV/r while PIs are known to have different profiles of liver toxicity [23].

As any study conducted in real life, this study has limitations. Data are collected at each routine visit assessment and are limited to the medical file records; for instance, data on treatment dosage and on adherence as well as data on hepatitis disease (severity and treatment) are not detailed; clinical and biological data were not completed at every visit; thus those data do not participate to the assessment of the primary endpoint.

Only descriptive data are here-described and the naïve / experienced patients' status is the single confounding factor herepresented; however when we studied the risk of treatment discontinuation using adjusted regressions we obtained similar results with no significant differences for co-infected patients compared to the others (relative risk $=1.12$ for co-infected patients, $\mathrm{p}=0.17$, in an adjusted Cox proportional hazard model).

\section{Conclusion}

Long-term studies including large and various populations are difficult to achieve, and real life setting cohorts provide additional information on drug use.

In this large cohort of patients with and without $\mathrm{HCV} / \mathrm{HBV}$ coinfection, we report no differences in long-term tolerability and durability of a FPV/r containing combination according to hepatitis co-infection.

\section{Acknowledgments}

This study was supported by ViiV Healthcare. The authors wish to thank patients and clinicians, Laurie Levy-Bachelot and Kappa Santé for the database analysis and the editorial support.

\section{References}

1. Alter MJ (2006) Epidemiology of viral hepatitis and HIV co-infection. J Hepatol 44: S6-9. 
Citation: Dellamonica P, Katlama C, Cabié A, Texier N, Finkielsztejn L (2014) Durability and Tolerability of Fosamprenavir/Ritonavir Containing Regimens in HIV-Infected Patients with or without Hepatitis B or C Co-Infection: Results from a Large French Cohort in Clinical Practice. J AIDS Clin Res 5: 372. doi:10.4172/2155-6113.1000372

Page 6 of 6

2. Merwat SN, Vierling JM (2011) HIV infection and the liver: the importance of HCV-HIV coinfection and drug-induced liver injury. Clin Liver Dis 15: 131-152.

3. Jones M, Núñez M (2011) HIV and hepatitis C co-infection: the role of HAART in HIV/hepatitis C virus management. Curr Opin HIV AIDS 6: 546-552.

4. Núñez M (2010) Clinical syndromes and consequences of antiretroviralrelated hepatotoxicity. Hepatology 52: 1143-1155.

5. Eron J Jr, Yeni P, Gathe J Jr, Estrada V, DeJesus E, et al. (2006) The KLEAN study of fosamprenavir-ritonavir versus lopinavir-ritonavir, each in combination with abacavir-lamivudine, for initial treatment of HIV infection over 48 weeks: a randomised non-inferiority trial. Lancet 368 : 476-482.

6. Pulido F, Estrada V, Baril JG, Logue K, Schewe K, et al. (2009) Long-term efficacy and safety of fosamprenavir plus ritonavir versus lopinavir/ ritonavir in combination with abacavir/lamivudine over 144 weeks. HIV Clin Trials 10: 76-87.

7. Carosi, Lazzarin, Stellbrink, Moyle, Rugina, et al. (2009) Study of oncedaily versus twice-daily fosamprenavir plus ritonavir administered with abacavir/lamivudine once daily in antiretroviral-naïve HIV-1-infected adult subjects. HIV clin trials 10: 356-367.

8. Smith KY, WeinbergWG, Dejesus E, Fischl MA, LiaoQ, et al. (2008) Fosamprenavir or atazanavir once daily boosted with ritonavir $100 \mathrm{mg}$, plus tenofovir/emtricitabine, for the initial treatment of HIV infection: 48-week results of ALERT. AIDS Res Ther 5.

9. Gathe JC Jr, Ive P, Wood R, Schürmann D, Bellos NC, et al. (2004) SOLO: 48-week efficacy and safety comparison of once-daily fosamprenavir /ritonavir versus twice-daily nelfinavir in naive HIV-1infected patients. AIDS 18: 1529-1537.

10. Fosamprenavir SmPC, EMA Jan 2013

11. Guidelines for the use of antiretroviral agents in HIV-1-infected adults and adolescents DHHS guidelines (2013).

12. European Guidelines for treatment of HIV infected adults in Europe guidelines (2012) EACS 6.

13. 2010 report under the direction of Pr Patrick YENI. Medical care of persons infected with HIV (2010). Recommendations of the expert group.13: 253-255.
14. Pérez-Elías MJ, Morellon ML, Ortega E, Hernández-Quero J, RodríguezTorres M, et al. (2009) Pharmacokinetics of Fosamprenavir plus Ritonavir in Human Immunodeficiency Virus Type 1-Infected Adult Subjects with Hepatic Impairment. Antimicrob Agents Chemother 53: 5185-5196.

15. Wood R, Gathe JC, Givens N, Sedani S, Cheng K, et al. (2013) Long-term safety study of fosamprenavir-containing regimens in HIV-1-infected patients. HIV Clin Trials 14: 183-191.

16. Esposito V, Chiodini P, Viglietti R, Parrella R, Parrella G, et al. (2011) Safety of fosamprenavir in a cohort of HIV-1-infected patients with comorbidities. In Vivo 25: 813-819.

17. Ha B, Wine B, Rodriguez-Alcantra F, Shaefer M (2012) Hepatic safety profile of fosamprenavir-containing cegimens in HIV-1-infected patients with or without hepatitis B or C coinfection. HIV clin Trials 13: 171-177.

18. Pineda JA, Pérez-Elías MJ, Peña JM, Luque I, Rodríguez-Alcantara F, et al. (2008) Low rate of adverse hepatic events associated with fosamprenavir/ritonavir-based antiretroviral regimens. HIV Clin Trials 9: 309-313.

19. Merchante N, López-Cortés LF, Delgado-Fernández M, Ríos-Villegas MJ, Márquez-Solero $\mathrm{M}$, et al. (2011) Liver toxicity of antiretroviral combinations including fosamprenavir plus ritonavir $1400 / 100$ ? mg once daily in HIV/hepatitis C virus-coinfected patients. AIDS Patient Care STDS 25: 395-402.

20. Pugliese P, Cuzin L, Cabié A, Poizot-Martin I, Allavena C, et al. (2009) A large French prospective cohort of HIV-infected patients: the Nadis Cohort. HIV Med 10: 504-511.

21. Blick G, Greiger-Zanlungo P, Gretz S, Han J, Dupree D, et al. (2012) Long-term efficacy and safety of once-daily fosamprenavir $1400 \mathrm{mg}$ boosted by ritonavir $100 \mathrm{mg}$ : the BOLD100 study. Int J STD AIDS 23: 18-22.

22. Macías J, Neukam K, Mallolas J, López-Cortés LF, Cartón JA, et al. (2012) Liver toxicity of initial antiretroviral drug regimens including two nucleoside analogs plus one non-nucleoside analog or one ritonavirboosted protease inhibitor in $\mathrm{HIV} / \mathrm{HCV}$-coinfected patients. HIV Clin Trials 13: 61-69.

23. Núñez M (2006) Hepatotoxicity of antiretrovirals: incidence, mechanisms and management. J Hepatol 44: S132-139. 